LIBRARY

gOYA. ONTARIO MUSEUM 
Digitized by the Internet Archive in 2011 with funding from University of Toronto 

Life Sciences Contributions

Royal Ontario Museum

LIBRARY

ROYAL ONTARIO MUSEUM

Contributions to the Biology of the Asian Caddisfly Family Limnocentropodidae (Trichoptera)

Glenn B. Wiggins

ROYAL ONTARIO MUSEUM LIBRARIES

З 1761050136639

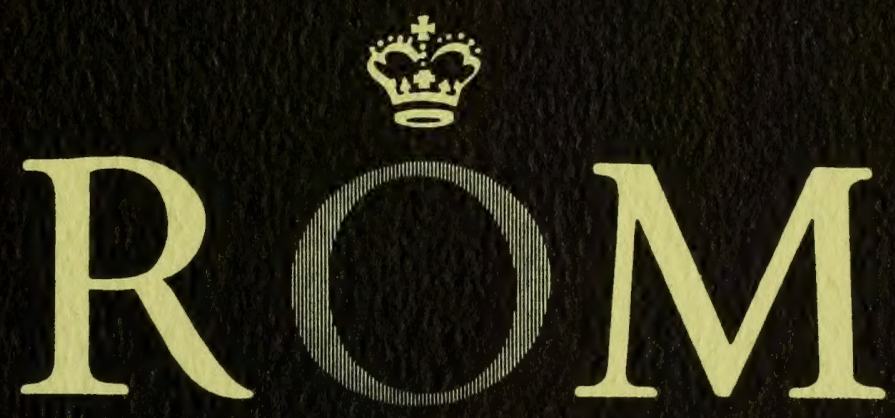



LIFE SCIENCES CONTRIBUTIONS

ROYAL ONTARIO MUSEUM

NUMBER 74

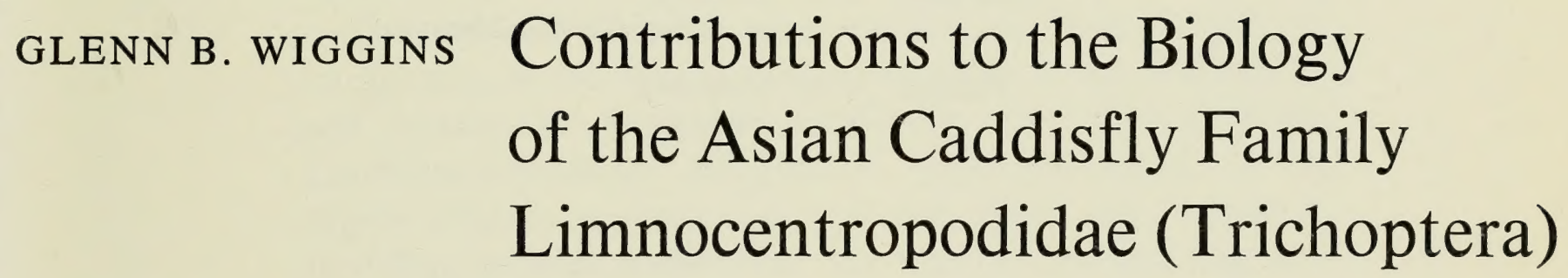

Publication date: 4 April 1969

Suggested citation: Life Sci. Contr., R. Ont. Mus. 


\section{PUBLICATIONS IN LIFE SCIENCES}

The Royal Ontario Museum publishes three series in the Life Sciences:

LIFE SCIENCES CONTRIBUTIONS, a numbered series of original scientific publications, including monographic works.

LIFE SCIENCES OCCASIONAL PAPERS, a numbered series of original scientific publications, primarily short and usually of taxonomic significance.

LIFE SCIENCES MISCELLANEOUS PUBLICATIONS, an unnumbered series of publications of varied subject matter and format.

All manuscripts considered for publication are subject to the scrutiny and editorial policies of the Life Sciences Editorial Board, and to review by persons outside the Museum staff who are authorities in the particular field involved.

LIFE SCIENCES EDITORIAL BOARD, 1969

Chairman: P. C. SWANN

Director, Royal Ontario Museum

Editors: G B. WIGGINS

R. L. PETERSON

GLENN B. WIGGINS is Curator of the Department of Entomology and Invertebrate Zoology, Royal Ontario Museum, and Professor in the Department of Zoology, University of Toronto.

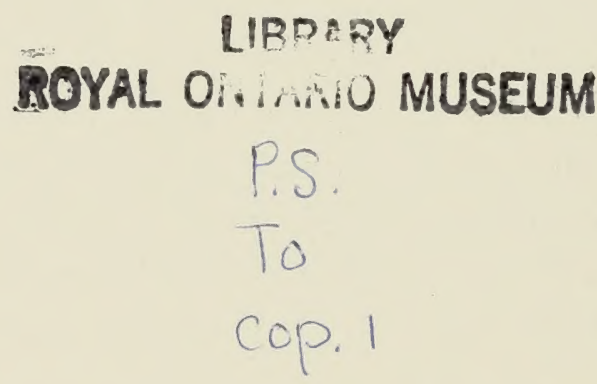

P R IC E : $\$ 1.00$

(C)The Royal Ontario Museum, 1969

100 Queen's Park, Toronto, Canada

PRINTED AT THE UNIVERSITY OF TORONTO PRESS 


\title{
Contributions to the Biology of the Asian Caddisfly Family Limnocentropodidae (Trichoptera)
}

\begin{abstract}
Of the eight species known in the Limnocentropodidae, the larva and pupa were known heretofore for only one- $L$. insolitus Ulmer from Japan. Described here are the larvae and pupae of three more species- $L$. mergatus Kimmins, $L$. rectus Kimmins and $L$. himalayanus Martynov, based largely on collections made by Dr. Fernand Schmid in northern India. The larva of another species from Thailand is also described, and a key provided for identifying larvae of these five species.

The unusual morphological features of these larvae are interpreted, in the light of field notes made by Dr. Schmid, to add considerably to existing knowledge of the biology of the Limnocentropodidae. Adaptations fitting the larvae to be highly efficient predators in turbulent rivers are discussed, including several remarkable features of case-building behaviour.

Evidence is presented to show that L. himalayanus Martynov is a senior synonym of $L$. fletcheri Mosely. Variations in the male genitalia of $L$. himalayanus Martynov are illustrated. Diagnostic characters of the female genitalia in five species of Limnocentropus are illustrated and a key provided.
\end{abstract}

\section{Introduction}

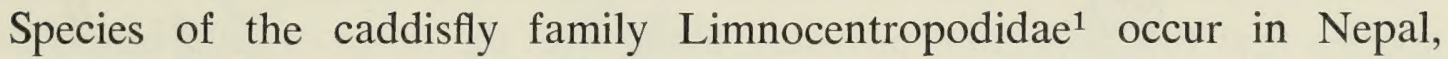
northern India, Burma, Thailand, China, Borneo and Japan, where they are largely confined to the rapid sections of rivers. With only one genus, now numbering eight species, the family is one of the smallest in the Trichoptera. Although knowledge of the adults of these species has been slowly accumulating since 1907, and has been summarized by Kimmins (1950), the only information available on the immature stages has come from one species in Japan. This has been sufficient, however, to show that the group is one of unusual interest because of some remarkable features of morphology and behaviour.

\footnotetext{
${ }^{1}$ In accordance with Par. 54, Copenhagen Decisions on Zoological Nomenclature (1953), the name of this family became Kitagamiidae Tsuda (1936). However, by Art. 40, Int. Code Zool. Nomen. (1961), retention of the family name Limnocentropodidae (emendation of Limnocentropidae Tsuda, 1942, by Ulmer, 1951), based on the widely used generic name Limnocentropus Ulmer (1907), is clearly in the best interests of stable nomenclature for the group.
} 
The observations presented here are significant because they provide, for the first time, knowledge of the immature stages of several additional species, along with detailed observations on their behaviour. Most of the material was made available to me for study by Dr. Fernand Schmid of the Entomology Research Institute, Ottawa, and was collected during his extensive field work in India from 1959 to 1962. Most of the adult specimens are in Dr. Schmid's collection; the immature specimens are deposited in the Royal Ontario Museum. A few specimens from other sources have also been studied, and are so designated.

Although most of the new information relates to the larval and pupal stages, observations are also offered on certain aspects of morphology and behaviour of the adults.

\section{Genus Limnocentropus Ulmer}

Larvae. Larvae of the Limnocentropodidae can be distinguished from all others by the set of four sclerotized plates on the meso- and metanota, the large sclerite on the dorsum of the first abdominal segment, the patches of stout bristles on the meso- and metasterna and also on the sternum of the first abdominal segment (Fig. 1). The long stalk or mooring cable of the larval and pupal cases (Fig. 8) is a unique characteristic of this family. Because a thorough description has been given by Ulmer (1955) for the larva and pupa of this family (actually based on the single species $L$. insolitus Ulmer from Japan, but generally adequate for the family as now known), this information need not be repeated. Offered here are general observations and illustrations which augment Ulmer's work, along with diagnostic information for the immature stages of the species not previously available for study.

It is first of all clear that larvae of this genus are among the most highly specialized predators in the order Trichoptera. The robust and muscular appearance of the larvae is alone sufficient to suggest the predatory habit, and indeed there has already been speculation along these lines (Ulmer, op. cit.). But with the extensive series of Limnocentropus larvae of several species that this collection provides, along with the notes of field observations on the living larvae made by Dr. Schmid, it is now possible to establish some direct relationships between morphology and behaviour.

Examination of the gut contents of several larvae shows their food to consist largely of insects. Larvae of chironomids and caddisflies are represented, among the latter a limnephilid related to Neophylax. A few strands of filamentous algae are also present, and there are quantities of finely particulate material which appear to be of plant origin. Thus, although the predatory habits of the larvae are clear enough, they evidently do ingest plant materials as well.

Dr. Schmid's observations indicate the effective manner in which predation is carried out. The larva locates itself with the anterior end of the case facing into the current. The case is firmly fastened to a large rock by the silken mooring cable, thus enabling the larva to maintain its position in strong current while still permitting all of its legs to be devoted to food 


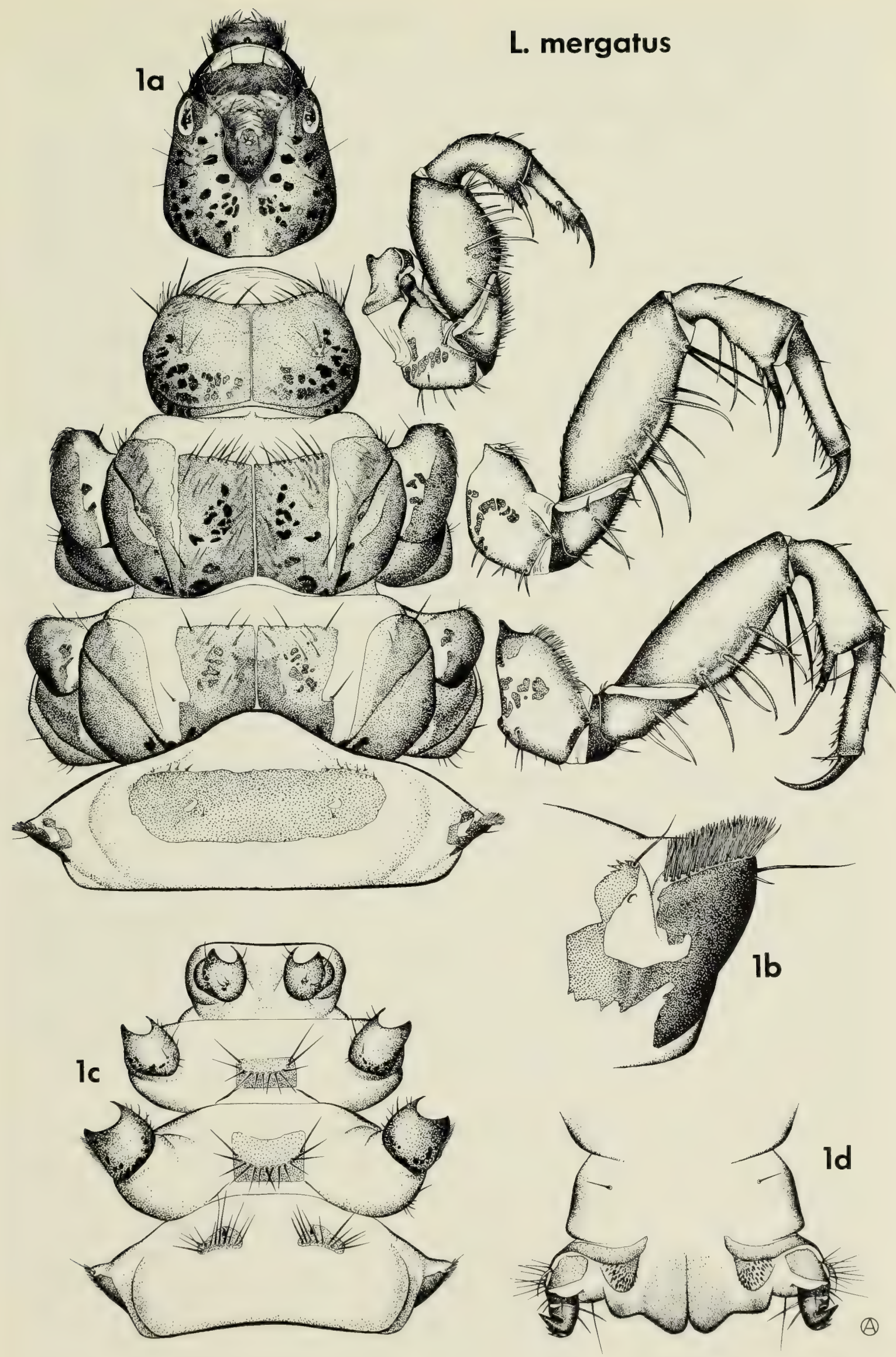

Fig. 1 Limnocentropus mergatus larva: $a$, head and thorax in dorsal view, legs in lateral view; $b$, lateral hump of first abdominal segment; $c$, thorax and first abdominal segment, ventral view; $d$, posterior end of abdomen, ventral view. 
gathering. The thorax of the larva is extended from the case and curved upward and backward (evidently not the abdomen as indicated by Botosaneanu, 1963). The legs are outstretched and held in the current above the level of the case.

Examination of the detailed structure of the legs demonstrates how they have been adapted for this type of food gathering. The large and robust larva of L. mergatus (Fig. 1a), made available for the first time by this collection, provides a striking example. The legs are very much enlarged and elongated, somewhat as in Brachycentrus. The femora of the second and third pairs of legs are beset with two opposing rows of four extraordinarily stout, long spines; the anterior femora also bear stout spines. The tibiae of all three pairs of legs carry stout single spines, the apical one on a very long tubular base. The sieve function of the outstretched legs, beset as they are with these spines, is therefore clear. By closing the tibia upon the femur, between the two rows of stout spines, it seems equally clear that the larva can add to its already awesome equipment the increased efficiency of movable pincer-traps to firmly grasp the small creatures swept within its reach by the current. Contributing to the powerful appearance of the legs, and probably to their performance as well, are the much-enlarged pleural portions of the meso- and metathoracic segments. The pleural sclerites of each of these segments are also very much broader than they are in other caddisfly larvae. Large muscles lie within these parts, and presumably they bestow added muscular strength for the vigorous actions of the legs.

Another unusual feature of the larvae of Limnocentropus is the patches of stout bristles on the sternal areas of the mesothorax, the metathorax and the first abdominal segment (Fig. 1c). Meeting the current as the larva does, with legs outstretched and sternal areas exposed, these bristles could well serve to impede the course of food items brought against the sternal area by the current, and/or to receive stimuli for the presence of such food items. Among other features of significance is the pad of small accessory denticles or hooks situated beside the stout anal hooks (Fig. 1d). These would likely provide additional firm purchase on the inside of the case for larvae obliged to extend themselves well out of the case and to retract rapidly.

One of the most impressive characteristics of Limnocentropus larvae is the unusually heavy endowment of sclerotized plates on the meso- and metathorax. Localization of the patches of hairs on the dorsal plates suggests that the mesal plates represent a fusion of enlarged seta-bearing sclerites sa1 and sa2 (sensu Ross 1959), and that the lateral plates represent a much enlarged sclerite sa3. Even more remarkable for caddisfly larvae is the presence of a sclerite on the dorsum of the first abdominal segment. Ulmer (1955), whose conjecture about the function of the legs of these larvae is now largely confirmed, suggests that the sclerotized plates serve to protect those portions of the larva which have to be extended far out of the case in the course of feeding. At least equally tenable, it seems to me, is the interpretation that these sclerotized plates are necessary to reinforce the integumental origins of the highly developed muscles in 
predators as active as Limnocentropus. Tindall (1963:472), in a study of the musculature in larvae of Limnephilus, believes both factors are involved. In Limnocentropus, it appears, in fact, to be the ventral areas of the thorax which are the more exposed, according to Dr. Schmid's observations. This suggests that for Limnocentropus larvae the sclerotized plates do function in large measure as integumental reinforcement to resist muscular contraction.

Perhaps to be interpreted in much the same way is what appears to be the stout triangular extension of the gular sclerite on to the base of the labium (Fig. 4). This quadrangular sclerite bears across its widest transverse dimension a stout inner ridge, a section of the anteroventral margin of the head capsule. The triangular portion anterad of this ridge appears to correspond to what Nielsen (1942) terms the pregula, and the part posterad of the ridge the postgula. In recent work by Badcock (1961) and Hinton (1963), the pregula of Nielsen is said to be part of the labium. In any event, in Limnocentropus larvae the two triangular parts of this quadrangular sclerite do not separate at ecdysis. The high degree of sclerotization on the labium in this genus, both in the large gular sclerite, in plates immediately laterad, and in the unusually large sclerites of the submentum immediately anterad, is most unusual among the larvae of the case-building Trichoptera.

Another interesting modification of the head is the rich development of hairs along the lateral margins of the frontoclypeus (Figs. 5-7). In most families the larvae usually have three pairs in these positions, and therefore it is likely that some particular function is served for the limnocentropodids by these hairs. Possibly this is an enhanced sensory capacity for the detection of potential prey organisms in the approaching current.

Larval Behaviour. The larval case is cylindrical, tapered and somewhat curved in all species now known. In some species the cases appear to be made consistently of plant materials, in others of mineral materials, and in one species the two are evidently selected at different times. The posterior opening of the case is circular, completely open, and not restricted with silken mesh or other materials. It is curious to note that the cases are often fixed to surfaces in such a position that their curvature is directed away from the substrate. In many of the other case-making families characteristic of streams, the cases are borne with the curvature towards the substrate.

The mooring cable of the case has an outer layer of interwoven strands of silk (Figs. 8, 11). The cable is firmly fastened to the anterior end of the case on its outer surface, and upon the substrate the silken strands radiate out into an adhesion disc. Sectioning through the cable shows that it has a thick inner core of plant material and silk. The mooring cable is extremely tough and is an elegant solution to the problem of providing firm anchorage in fast current.

Dr. Schmid records that when stones bearing the cases of mature larvae are removed from the water, the cables stand rigid and do not bend under the weight of the larvae and their cases; and the larvae remain concealed 

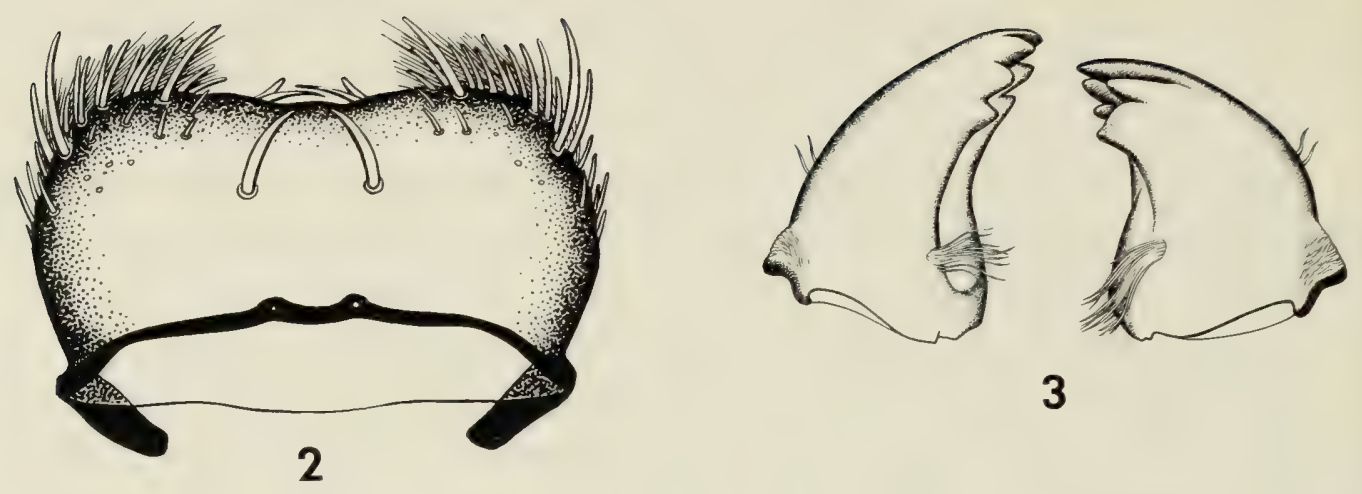

3

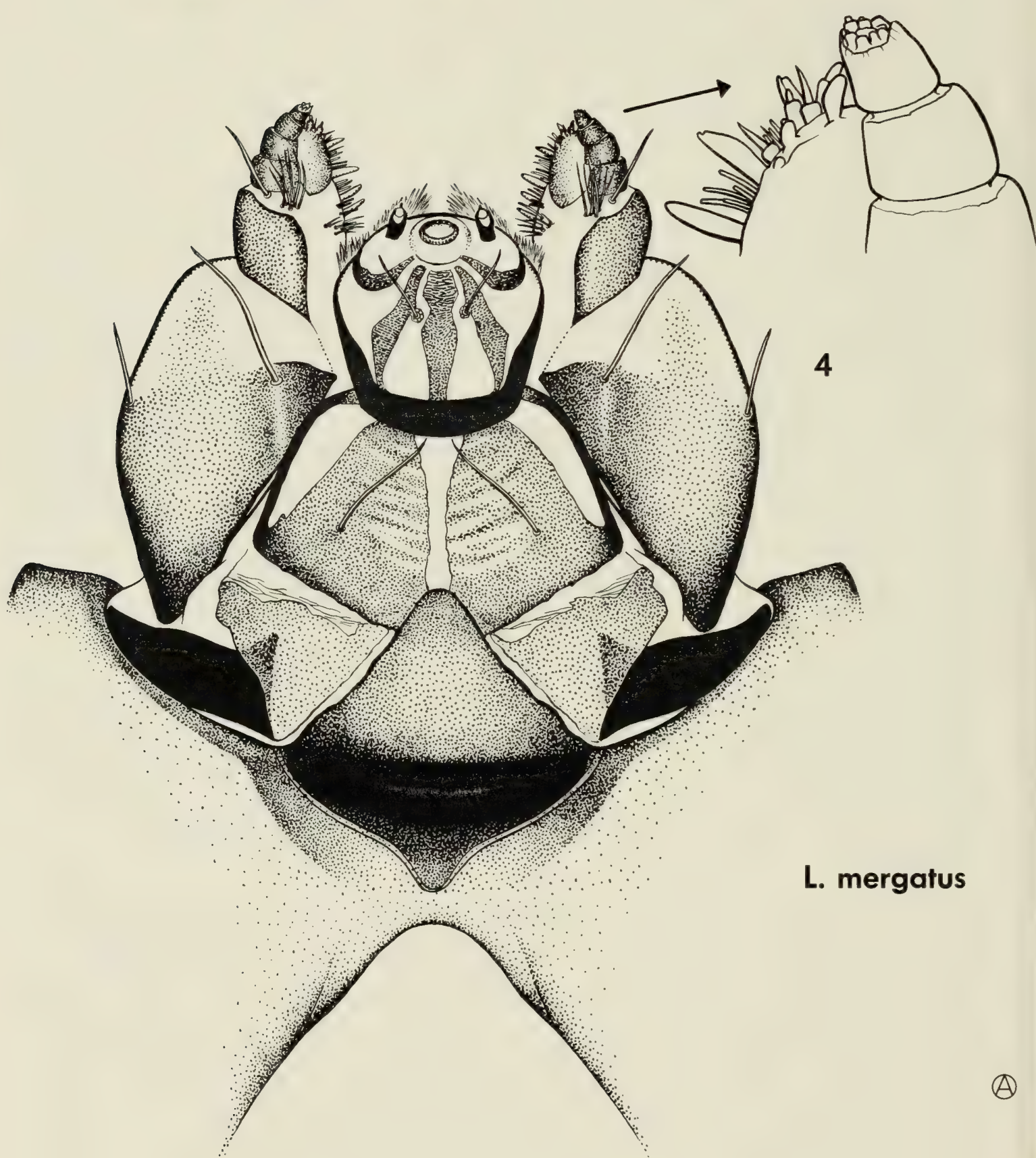

Figs. 2-4 Limnocentropus mergatus larva. 2. labrum, dorsal view. 3. mandibles, dorsal view. 4. labium and maxillae with their connections to the ventral surface of the head capsule, enlarged view of tip of maxilla at right. 

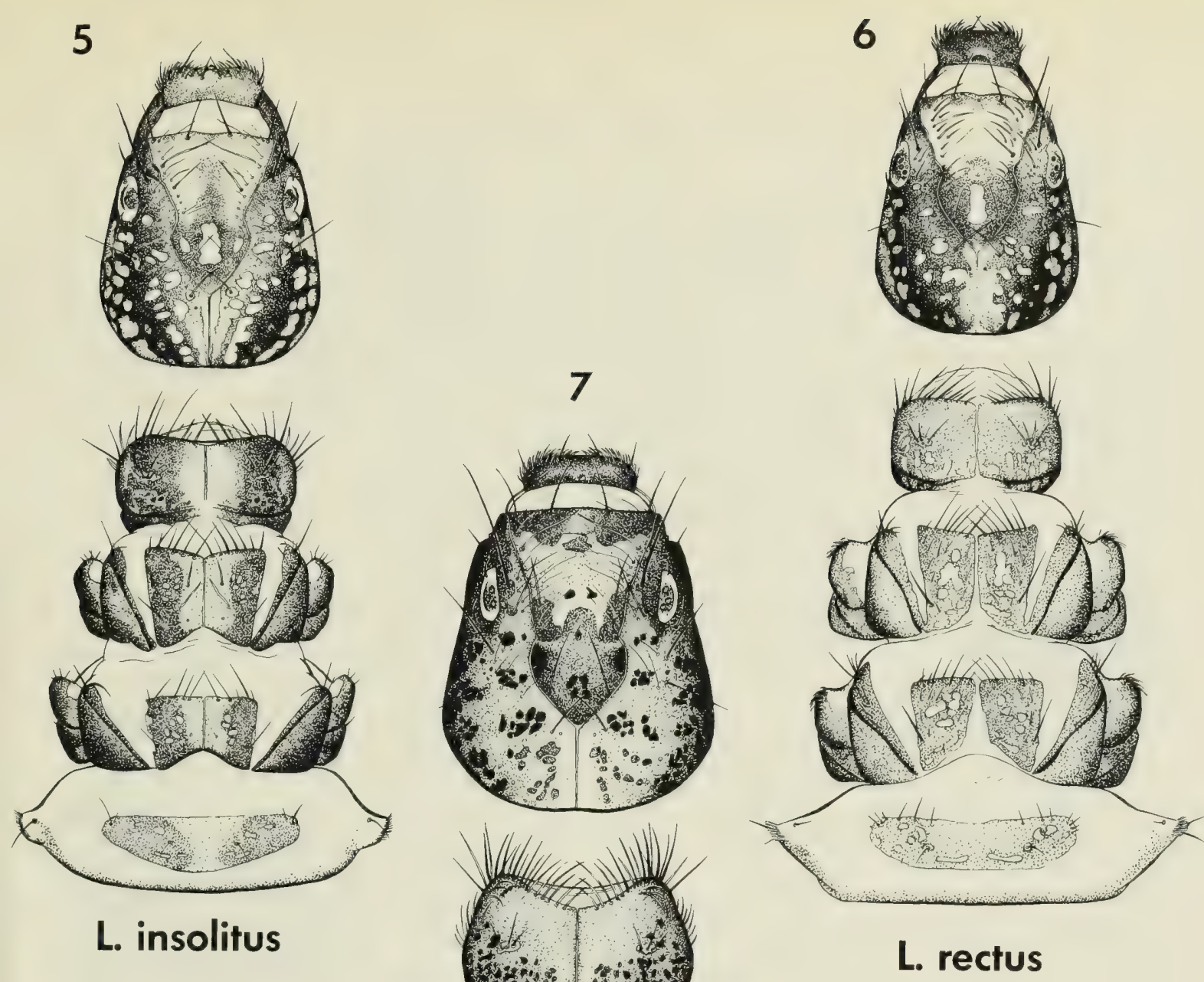

L. insolitus
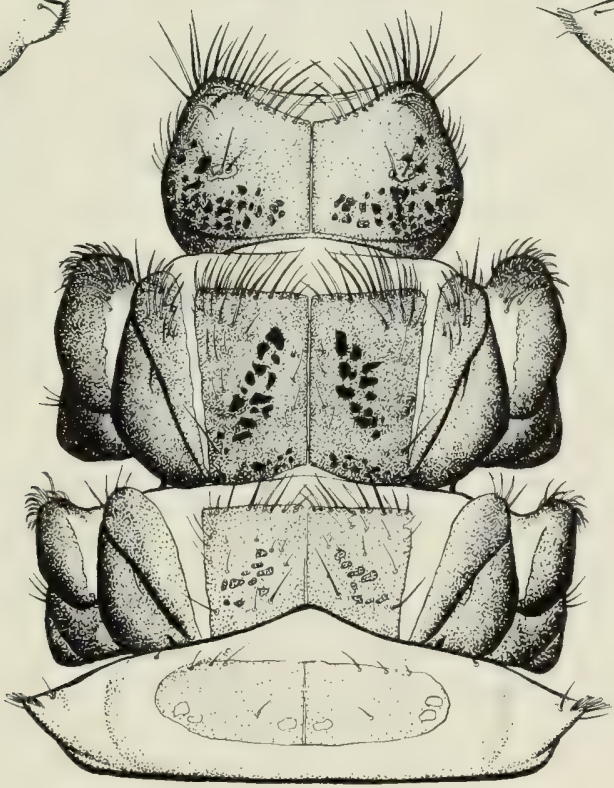

\section{L. sp.}

Figs. 5-7, Limnocentropus spp. larvae, head, thorax and first abdominal segment (head relatively more enlarged), dorsal view: 5. L. insolitus. 6. L. rectus. 7. L. sp. (Thailand).

within their cases for some time. Young larvae, however, (length $\pm 10 \mathrm{~mm}$; Assam, Kalaktang, 10 Oct. 1961, L. himalayanus ?) were observed to have a short, very soft and flexible mooring cable. When a rock bearing these cases is removed from the water, the cables bend under the weight of the larvae and their cases. Many of these young larvae were seen cutting their cables and crawling away, a behaviour not observed in more mature larvae where the cables are much stouter.

Dr. Schmid also observed that when the current is stopped by some artificial means, the larvae withdraw into their cases. When the current is established again the cases swing rhythmically in the current and all at once 
the larvae protrude and bend upwards again in their normal food-gathering position.

As the time for pupation approaches, the larvae make certain changes in their cases. The silken mooring cable is shortened (Fig. 9a), very much so in L. himalayanus (Fig. 10a), and this same species is unique among the larvae now known for the curious flange of fine stones built around the anterior end of the case. Modification of the posterior end of the case comprises, for most species, a funnel-shaped closure to the open end. In lateral view (Figs. 9a, d) this tapers more strongly on the inner side than on the outer, and in ventral view (Fig. 9c) the mid-line of the inner side is seen to be a silken seam, which completely seals the case except for a small circular opening at its origin. Ulmer (1955) was of the opinion that this funnel-shaped closure was, in $L$. insolitus, an extension added to the larval case. I am inclined to think rather that the larva actually removes a section of the wall of the case, and then fastens the two edges together with silk in the manner illustrated (Fig. 9). Evidence for this is derived largely from the larval case of $L$. mergatus in which the posterior third or so is consistently made of bark fragments and the remainder mainly of small flat mineral pieces. The composition of this apical piece is about the same in the pupal cases, with no evidence of pieces having been added. Furthermore, the sand-grain pupal cases of $L$. himalayanus show no evidence of the demarcation near the posterior end that would be expected if a section were added to it, nor is such a line apparent in plant-fragment pupal cases of $L$. insolitus in the ROM collection. Consistent with this view is the discovery of one larval case of $L$. mergatus with a symmetrical excision from the posterior end, which if joined along the edges would result in a terminal closure of the sort seen to be typical for that species (Fig. 9). In one species, L. rectus (Fig. 11), the pre-pupation behaviour is so bizarre that it seems likely that a section is added to the posterior end beyond the termination of the sealed-off larval case, although again no line of demarcation is apparent in the sand-grain composition of the case. The completed pupal case (Fig. 11c) appears as though a lunate excision had been removed, and the walls fastened together again along the typical silken seam. The case is sealed on the inside with silk at the posterior edge of the lunate excision, and therefore the terminal opening is in a blind section of the case. And for L. rectus and himalayanus this sharp contrast in prepupation behaviour is all the more remarkable because morphological differences between the larvae have yet to be found. In all species the anterior opening of the case is sealed off with a silken membrane of the normal type, bearing an eccentric linear opening (Figs. 9b, 11b).

Perhaps central among the questions on the biology of these caddisflies which remain to be explained is the means by which the larva can lengthen or shorten the mooring cable or add to its case while still maintaining its position in the strong current. It is likely, too, that by its very position, suspended in the current and moored to a large rock, the supply of suitable case materials would be limited. Yet it is obvious from the uniform structure of the cases that a high degree of selectivity is exercised in the gathering 


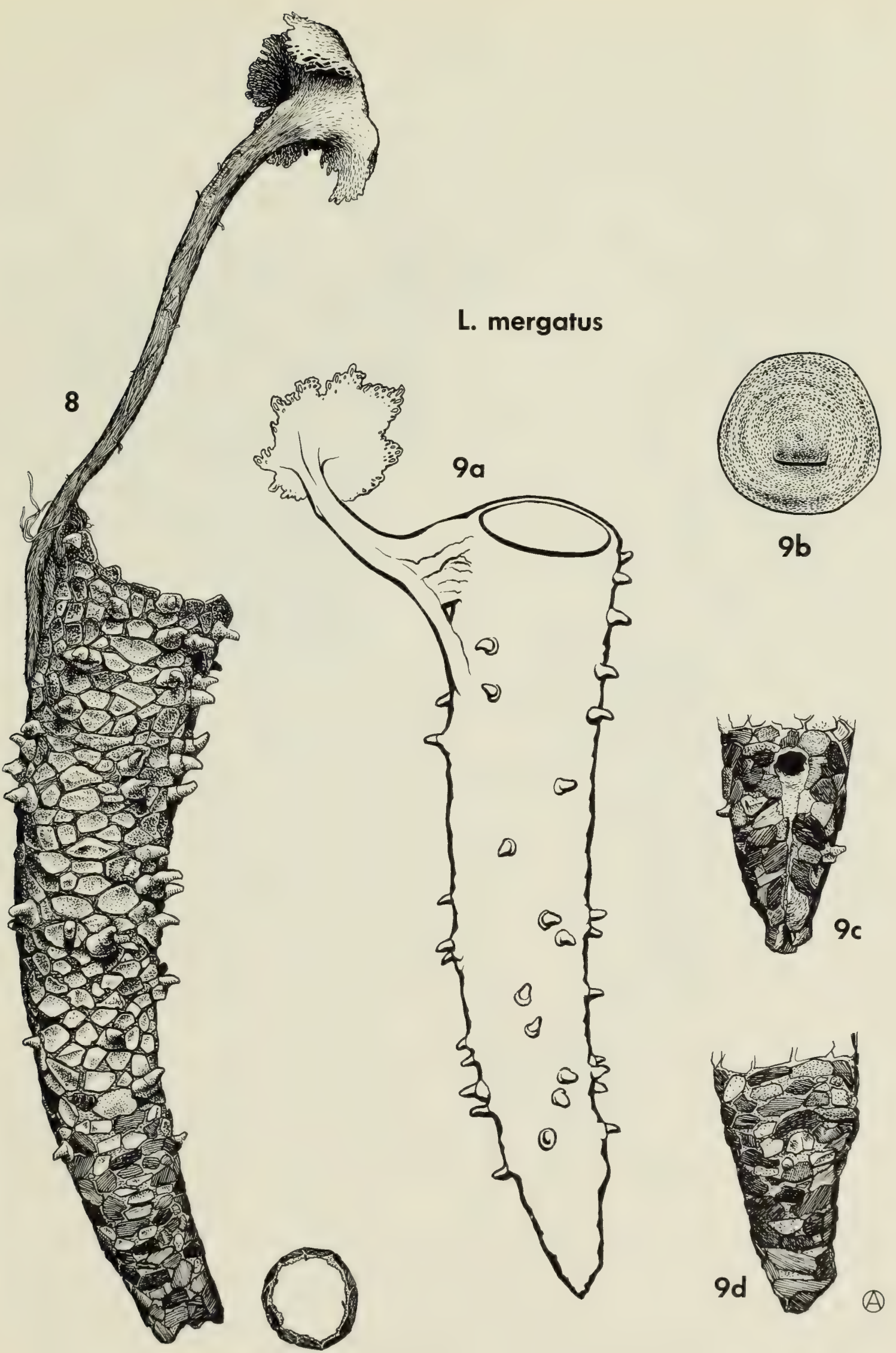

Figs. 8-9 Limnocentropus mergatus larval and pupal cases. 8. L. mergatus larval case, showing opening at posterior end. 9. L. mergatus pupal case: $a$, entire pupal case; $b$, silken membrane sealing anterior opening; $c$, posterior end of case, ventral view; $d$, posterior end of case, lateral view. 


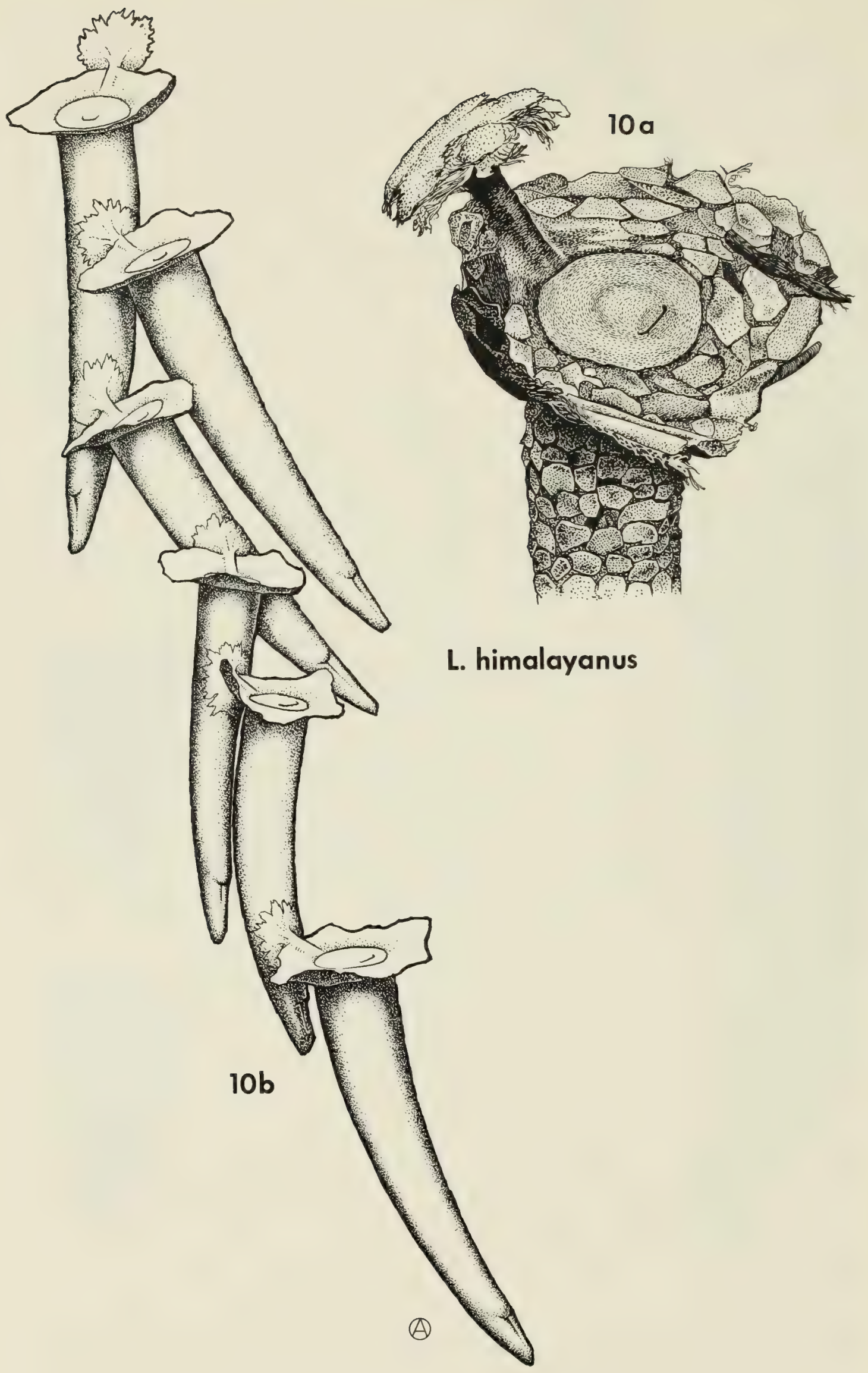

Fig. 10 L. himalayanus: $a$, anterior end of pupal case; $b$, pupal cases fastened together. 
of case components, and it must consequently be supposed that a rich and varied source of potential case materials is available. Perhaps small pieces of mineral or plant material which must always be carried along by a strong current are intercepted, inspected and used or rejected as appropriate to the building requirements of the larva. Should this be so, then at least some features of the highly developed sieve system of the larva may function to gather case materials as well as prey. Another possibility is that the larvae are more mobile, that they frequently move about with their cases, but the very stout disc of silk by which the case is firmly fastened to the substrate would suggest that this is not likely.

Specialization of the larvae of Limnocentropus for predation in strong water currents has several parallels in the brachycentrid caddisfly Oligoplectrum maculatum Fourcroy from Europe, the subject of a detailed study by Nielsen (1943). In both Oligoplectrum and Brachycentrus there is a striking similarity to Limnocentropus in the enlarged legs armed with stout spines, in the four elongate sclerites of the mesonotum (but not the metanotum), and in the habit of anchoring the case with silk to a firm substrate in strong current. It has been demonstrated by Nielsen (op. cit.) that the legs of $O$. maculatum also function as a sieve to intercept food organisms in the current, and to procure sand grains or small pieces of organic material for the larval case. Still further similarity is seen in the pre-pupation behaviour, where a flange of sand grains is constructed around the anterior opening of the case in $O$. maculatum, just as it is in $L$. himalayanus (Fig. 10). Nielsen suggests that this structure provides the increased pressure needed to maintain a flow of water adequate for respiration through the narrow pupal case. He also offers the view that the most important function of the collar is to exert a holding pressure against the current and thus to decrease its force at the mouth of the case, providing the emerging pupa some protection against the strong current into which it must directly emerge. The pupal cases of $O$. maculatum are found in dense aggregations, as those of $L$. himalayanus are reported to be, too (Fig. 10b).

Pupae. Limnocentropodid pupae seem to be more conventional, in morphology at least, than are the larvae when compared with other Trichoptera. Pupae of three species become known for the first time here, and it is of interest to see that the anal processes of all three are somewhat different in form (Figs. 12-14).

Adults. General morphological features of the adults have already been described by Kimmins (1950) and by Ulmer (1951). An interesting character of this family mentioned by Ross (1967) is the relatively welldeveloped sclerous articulating mandibles of the adult (Fig. 15). In other families of the limnephilid branch (sensu Ross 1967), the Brachycentridae, Phryganeidae, Limnephilidae, etc., these mandibles are reduced to small lobes (Crichton 1957), although in the Rhyacophilidae and certain other more primitive families the mandibles are similar to those of the Limnocentropodidae.

The male genitalia in Limnocentropus are simple in structure (Fig. 16), 
and rather homogeneous among the species. The body of the tenth segment is broadly fused with the ninth; the praeanal appendages are absent. The claspers are without a second segment. The phallus is reduced, composed of a long, tubular phallotheca, at the end of which is a short erectile endotheca, provided with two sclerotized pieces (reduced parameres) and internally with a well-defined phallotremal sclerite and ejaculatory duct.

The terminal abdominal segments of the females (Figs. 17-21) show little similarity to those in any of the other families of the limnephilid branch. They seem, in fact, to be unique in this line by the retention of the sternum of the eighth abdominal segment in what is presumably the primitive segmental condition, without modification or fusion with the sternum of the ninth to form a subgenital plate as in the Brachycentridae,
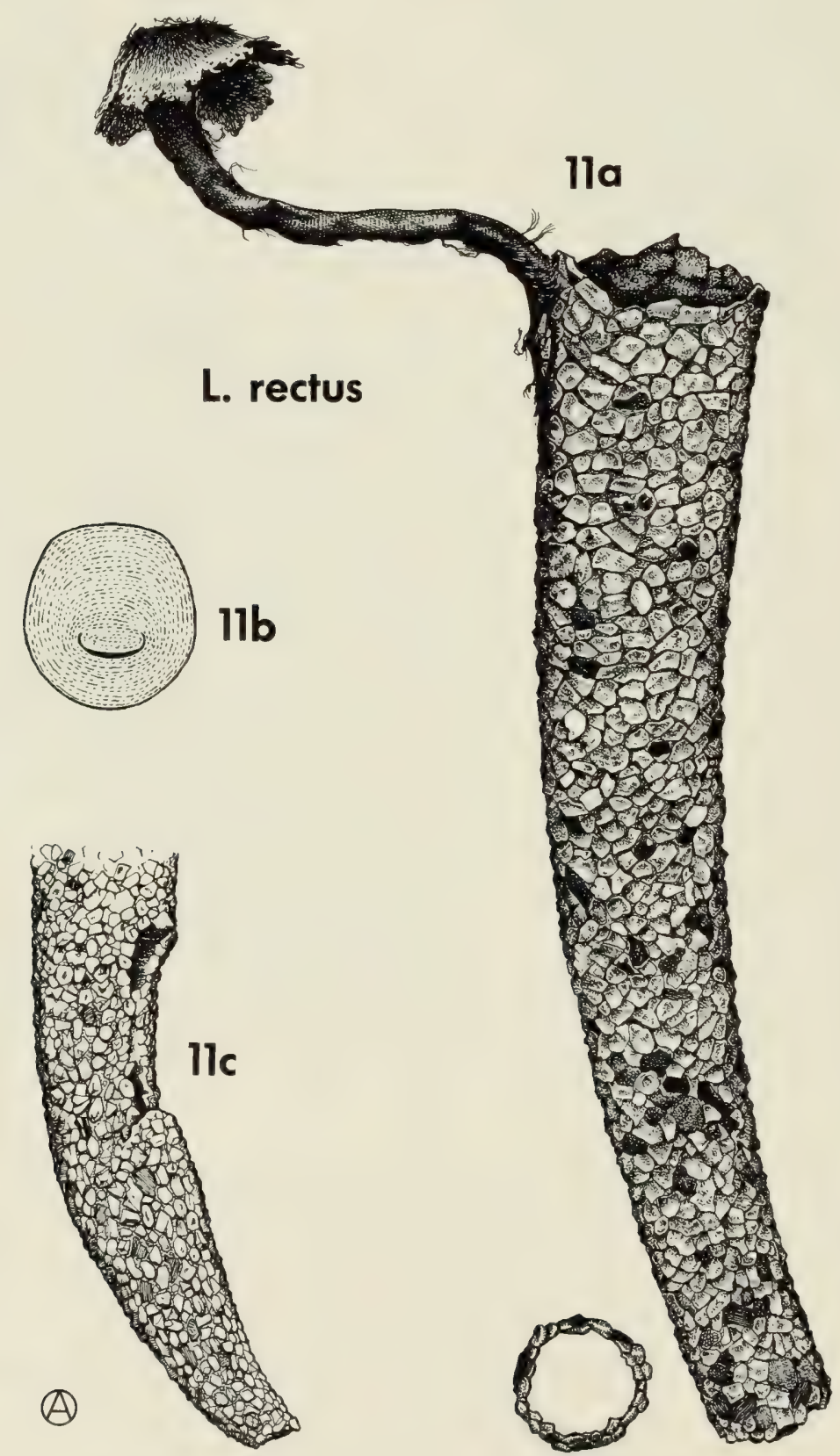

Fig. 11 L. rectus: $a$, larval case, showing opening at posterior end; $b$, silken membrane sealing anterior end of pupal case; $c$, posterior end of pupal case. 

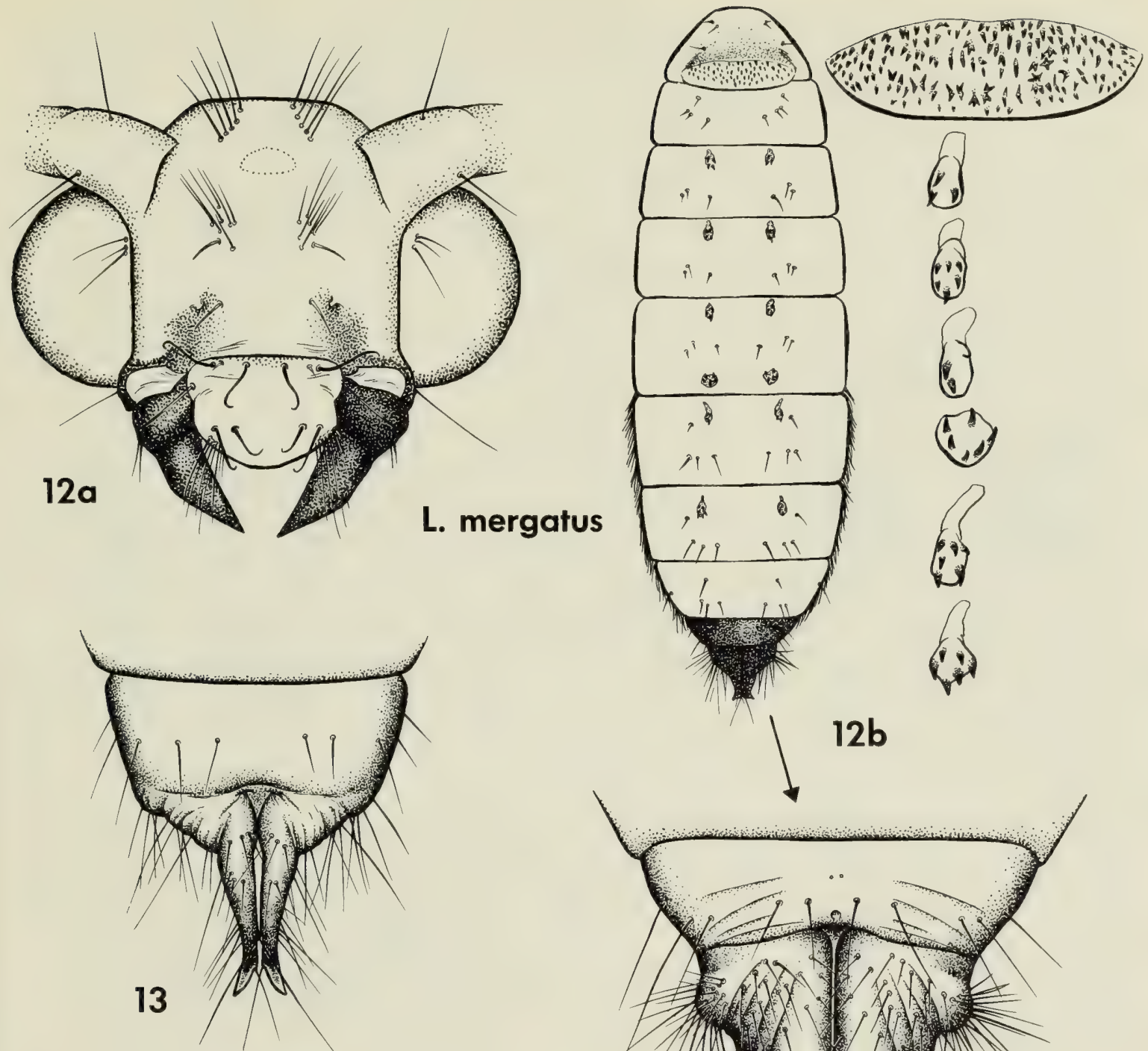

L. rectus

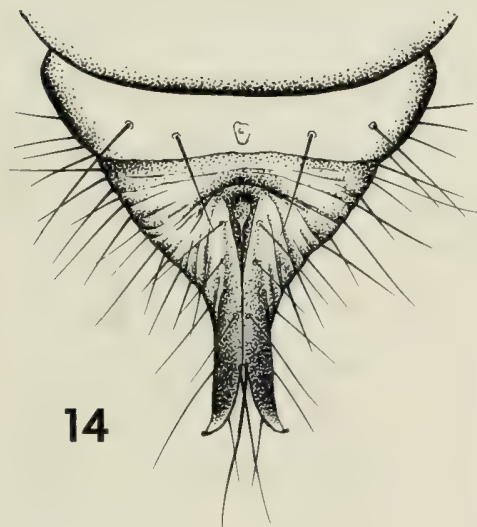

L. himalayanus

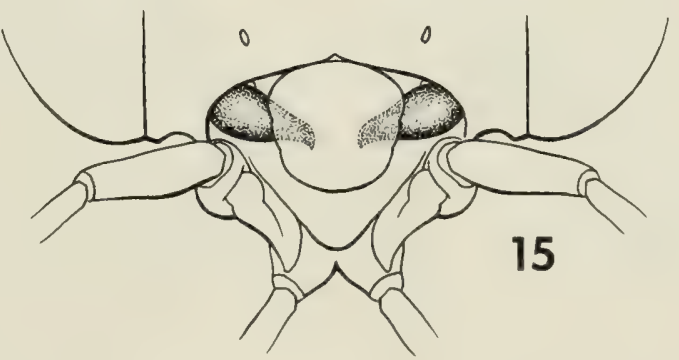

Figs. 12-15 Limnocentropus spp. 12. L. mergatus pupa: $a$, head, front view; $b$, abdomen with sclerotized parts enlarged, dorsal view. 13. $L$. rectus anal processes of pupa, dorsal view. 14. L. himalayanus anal processes of pupa, dorsal view. 15. L. himalayanus male, mouth parts showing mandibles. 
Phryganeidae, Limnephilidae, etc. The sternal portion of the ninth segment is flattened and bears a median and relatively more sclerotized and pigmented area which has a shape distinctive for each species (Figs. 17-21). A key to the females of five species is offered at the end of this paper.

An interesting observation of Dr. Schmid's concerns the behaviour of adults of Limnocentropus. Teneral specimens retained overnight in a box of dry leaves to harden were so active that by morning their wings were severely damaged and their dense pilosity entirely lost. Adults of other groups, Himalopsyche, Stenopsyche and Eubasilissa for example, always remained inactive in similar circumstances.

Habitat and Distribution. The waters from which these larvae of Limnocentropus were collected range from rivers of 30 feet or so in width to small rivulets. They are most abundant in rivers such as the Bhairabkunda Chu, where in fact pupae of three species-L. mergatus, rectus and himalayanus-were taken in a single collection (Assam, Lifakpo, $3100 \mathrm{ft}$, 15 May 1961). This is described as a very turbulent, medium-sized river in dense jungle, flowing over a rocky bed supporting heavy algal growths. Collection sites in general range in elevation from 1800 to 9000 feet.

The present range of the family extends from Japan and Borneo, through Thailand, Burma, and evidently parts of China, to Assam. There the group occurs to the south of the Brahmaputra River in Manipur and the Khasi Hills, and to the north in a narrow band of the Himalayas, largely in the foothills but with some extensions into the heart of the range, through Sikkim and Nepal, at least as far west as Pauri Garhwal, but evidently not to Kashmir.

Phylogenetic Considerations. In his suggested phylogeny of the families of Trichoptera, Ross (1967) postulates that the Limnocentropodidae are the most primitive living family of the limnephilid branch. The best evidence for this is that adults of the Limnocentropodidae have the primitive complement of five segments in the maxillary palpi of both sexes, well-developed ocelli, articulating sclerous mandibles, and a primitive set of head sutures; in the larvae a prosternal horn is not present. In the Limnocentropodidae, Ross identifies two specializations of the larva-the sclerites on the mesoand metanota, and the setate plates on the sterna of the same two segments. From the evidence presented here on the biology of the limnocentropodids, it seems reasonable to interpret these two features as specializations of predaceous sieve-feeders. It seems, in fact, that most of the unusual features of the morphology and behaviour of Limnocentropus larvae are directly related to their successful, although geographically limited, exploitation of this niche. This interpretation is further strengthened by the parallel development of several of the same specializations in the sieve-feeding brachycentrid genera Oligoplectrum (Nielsen 1943; Wiggins 1965), and Brachycentrus (Mecom and Cummins 1964).

Some comments are offered here on the proximity of the Brachycentridae to the Limnocentropodidae in the phylogenetic interpretation proposed by 


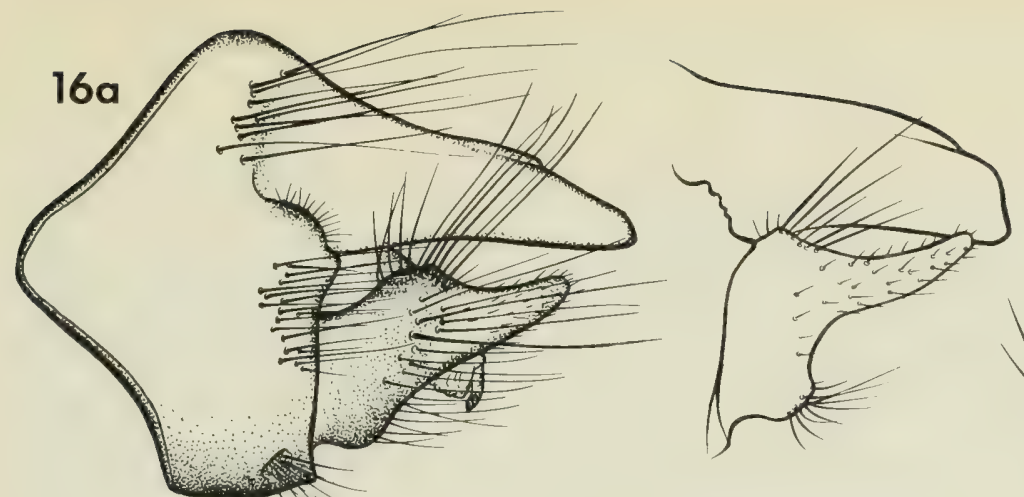

L. himalayanus
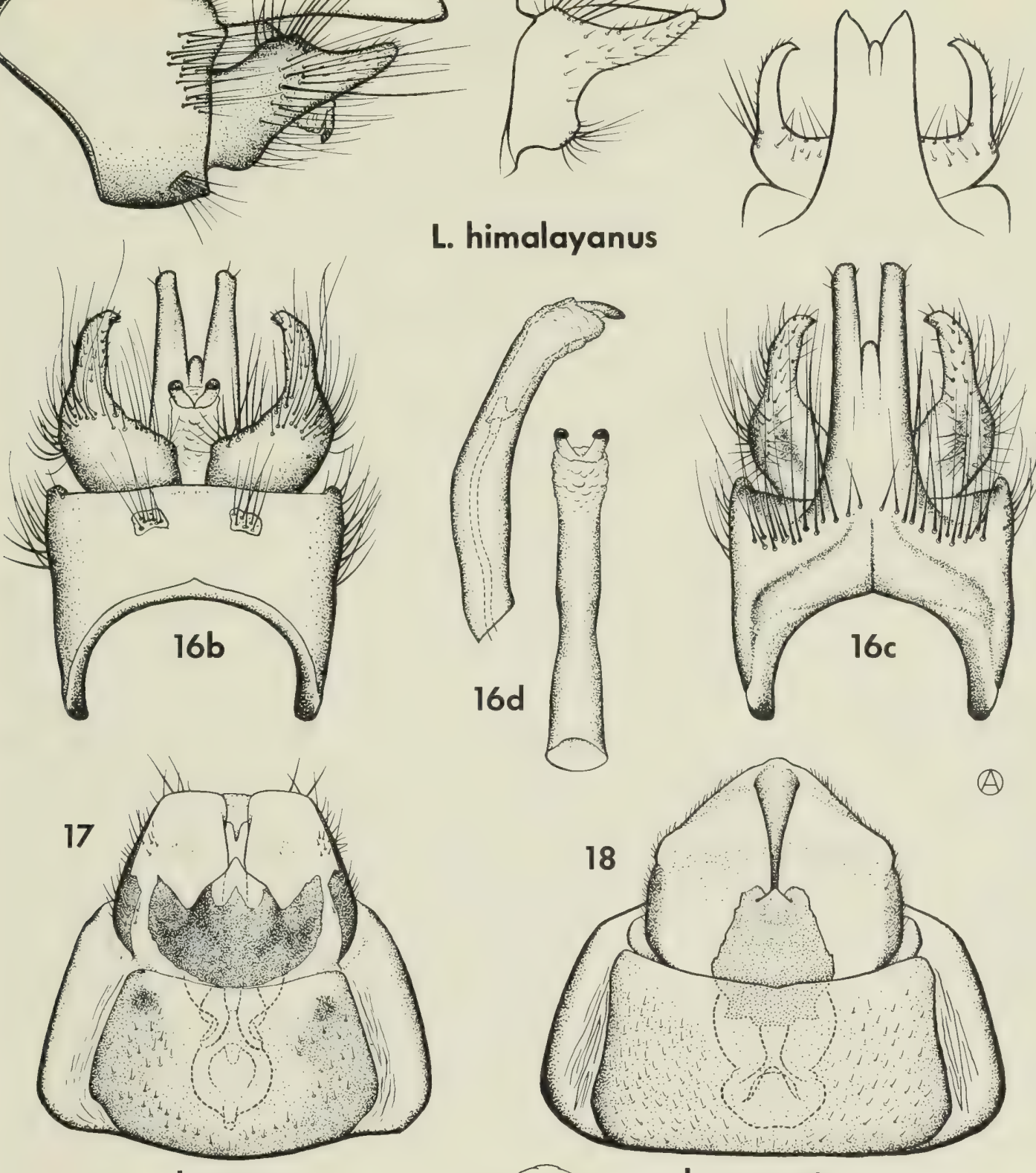

L. rectus

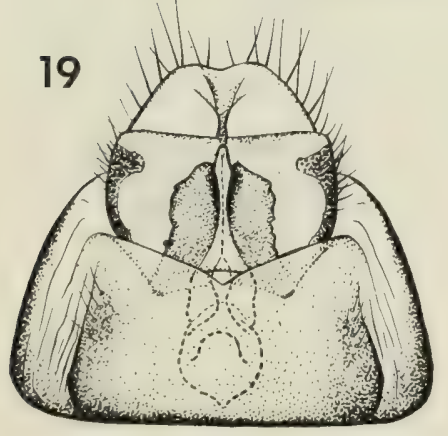

L. himalayanus

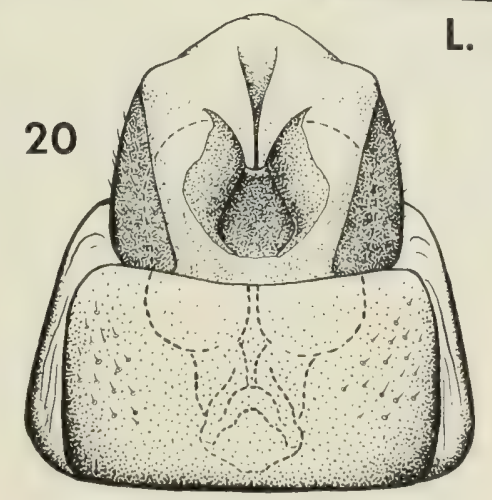

L. insolitus

(A)

Figs. 16-21 Male and female genitalia in Limnocentropus spp. 16. L. himalayanus male genitalia (Sikkim, Singbeng, 26 April 1959): a, lateral view with variant (Assam, Kameng F. D., Kujjalong, 2830 June 1961); $b$, ventral view; $c$, dorsal view with same variant; $d$, phallus, lateral and ventral views. 17. L. rectus female genitalia, ventral view. 18. L. mergatus female genitalia, ventral view. 19. L. himalayanus female genitalia, ventral view. 20. L. insolitus female genitalia, ventral view. 21. L. moselyi female genitalia, ventral view. 
Ross (op. cit.). It is suggested there that following the derivation of the line from which the Limnocentropodidae arose, an Ancestor 9 gave rise to two lineages: one giving rise to the Brachycentridae, in which $\mathbf{M}_{4}$ remained in the fore wing of the female and the maxillary palpi of the male became three-segmented; and the other giving rise to the Phryganeidae, Limnephilidae, etc., in which the prosternal horn of the larva evolved, and in which $\mathbf{M}_{4}$ was lost from the fore wing of the female. Recent evidence shows that the brachycentrid genus Eobrachycentrus does have a small prosternal horn, and on the basis of this and certain other characters, is believed to be a primitive genus in the Brachycentridae (Wiggins 1965). (Perhaps it would be more precise to say that this structure resembles the prosternal horn in external features, but that until the true function and internal structure are known for this horn in all the families in which it occurs, direct homology remains unproven; for the present let it be assumed that that proof will be forthcoming. ) It is also true of Eobrachycentrus that $\mathrm{M}_{4}$ is not present in the fore wing of the females, and it seems, then, that the characters of the Brachycentridae would not necessarily require that the family be assigned to this phylogenetic position. It may also be noted that vein $\mathbf{M}_{4}$ is present in the fore wings of the females of several phryganeids, such as Oligostomis pardalis (Walker), Fabria inornata (Banks), Agrypnia spp., Phryganea spp., Ptilostomis spp., Eubasilissa spp., and in the phryganopsychid Phryganopsyche latipennis (Banks) (Wiggins 1959). On the basis of the characters thus far considered, then, it would seem at least equally valid to derive the Brachycentridae from Ross' Ancestor 12, where three-segmented maxillary palpi in the males are already postulated. A closer relationship between the Brachycentridae and the Limnephilidae, Lepidostomatidae, etc. is also indicated by evidence from the terminal abdominal segments of the females, presented above. The male genitalia of the brachycentrid genera cover a fairly wide range of morphological types, but none of these seems to lend any particular reinforcement to a close relationship between the Limnocentropodidae and the Brachycentridae. One result of this alternative interpretation is that in the phylogeny of the primitive case-making families the sequence of rhyacophiloid stock $\rightarrow$ limnocentropodid stock $\rightarrow$ phryganeid stock would achieve a higher degree of homogeneity in what seem to be essential features of morphology in both larvae and adults. 


\section{Key to the larvae of Limnocentropus (in part)}

1. A solid dark band extending across the anterior border of the frontoclypeus; muscle scars on the dorsum of the head darker than the surrounding area (Figs. 1a, 7)

Anterior border of the frontoclypeus without a dark band; muscle scars on the dorsum of the head lighter than the surrounding area (Figs. 5, 6)

2. Sclerotized plates on sternum of first abdominal segment each with a row of some 14 or more stout bristles; anterolateral corners of pronotum with a patch of stout hairs; lateral margins of pronotum tapered anterad (Fig. 7) (Thailand)

Sclerotized plates on sternum of first abdominal segment each with a row of some 8-11 stout bristles (Fig. 1c); hairs on the anterolateral corners of pronotum neither as stout nor as numerous as in the preceding species; lateral margins of pronotum not tapered anterad as much as in the preceding species (Fig. 1a) (central and eastern Himalayas)

L. mergatus

3. Mesal sclerotized plates of mesonotum and metanotum of uniform base colour; the muscle scars in the central portion of each plate coalescing to form a much lighter area (Fig. 6); abdominal segment IV without a gill, or in some specimens with a very small papilla in the posterodorsal position

Mesal sclerotized plates of mesonotum and metanotum with the mesal portions less darkly pigmented than the lateral (Fig. 5); abdominal segment IV with a well-developed gill in the posterodorsal position ( $\mathrm{Ja}$ pan, China)

L. insolitus

4. Preceding pupation: posterior end of case modified by the larva in such a way that a silken seam runs from a small circular opening to the posterior end of the case; in lateral view the end of the case tapers rapidly along the seam line (as in Fig. 9d); larva constructs a conspicuous flange of small stones around the anterior opening (Fig. 10a) (central and eastern Himalayas, Burma)

Preceding pupation: posterior end of case modified by the larva in such a way that the silken seam and circular opening lie in a rectangular excision some distance anterad of the posterior end of the case (Fig. 11c); larva does not construct a flange of stones around the anterior opening of the case (Assam, West Bengal)

L. himalayanus

L. rectus 


\section{Limnocentropus mergatus Kimmins}

Limnocentropus mergatus Kimmins 1950, p. 597, fig. 5.

Larva (Figs. 1-4). Length of full-grown larva $22 \mathrm{~mm}$. This is one of the largest larvae yet known in the genus, and on this account the various morphological adaptations described above show especially prominently. Larvae of this species may be distinguished by the characters given in the key, and it is interesting to see how the dark muscle scars of this species and the one from Thailand provide such a marked contrast to the light muscle scars of the others now known. Morphological features of this larva, extensively illustrated and described in the preceding general section, require little additional comment here. Gills are short and thick, with a single one in the posterodorsal position on each of abdominal segments III to VIII inclusive. Hairs of the lateral line are very much reduced in number, to the extent that the line is represented by only a few hairs situated anteriorly on each of abdominal segments IV to VIII inclusive. A very narrow sclerite bearing four stout bristles extends across the posterior margin of segment IX.

The larval case (Fig. 8) appears to be built in two distinct parts. The apical third, or somewhat less, is largely comprised of small, thin pieces of bark, and is pliable. The remainder of the case is largely of mineral materials-many pieces of a mica-like substance and with a few thicker, but still small, pebbles. These materials are fitted together, along with a few pieces of bark, to provide an extremely tough and yet rather thin wall. The case of this species is distinctive from the others now known in having stout, corneous spikes scattered over its surface. These are evidently made by the larva with its own silk. They are usually formed upon the thicker pebbles in the case, and almost never are they situated on the more pliable apical portion of the case which is comprised largely of bark pieces. Cases of full-grown larvae of $L$. mergatus are approximately $25 \mathrm{~mm}$ in length, tapering strongly from an anterior opening of $5 \mathrm{~mm}$ diameter to a posterior opening of $2 \mathrm{~mm}$. The posterior opening is circular and not restricted with silken mesh or other materials. The mooring cable is shorter than the case itself, ranging from about 10 to $15 \mathrm{~mm}$ in length. Its attachment to the case is extended for some little distance along the side, but is not perpendicular to the long axis of the case as in other species because these larvae are usually attached to the vertical surfaces of stones.

Prior to pupation the mooring cable is usually shortened and thickened (Fig. 9a), and the adhesion disc on the substrate is often enlarged. The posterior end of the case is closed off as described in the preceding general section.

Larvae which appear to be of this species from a tributary of the Mandakini River in Pauri Garhwal (west of Nepal) have cases which are made entirely of pieces of bark. Only very infrequently is a corneous point to be found on these cases, and the walls are quite pliable throughout. The mooring cables are longer and more slender than in the spiked cases, being, on the average, approximately the same length as the case itself. 
Pupa (Figs. 9, 12). Features of what I take to be the typical pupa are as illustrated. The anal processes, characteristic for this species, are particularly stout and heavily sclerotized, suggesting that they are subject to considerable stress. Length of pupae: of $15 \mathrm{~mm}$; $918 \mathrm{~mm}$. Length of pupal cases: $25-30 \mathrm{~mm}$.

Pupal cases are also available for the larvae referred to above from the Mandakini River in Pauri Garhwal. These also are made completely of pieces of bark, with only a rare corneous point. The mooring cables are approximately as long as the cases, although in one specimen the cable is somewhat longer. From a series of pupae, without cases, collected in the same series as the intact pupal cases, it is possible to make out sufficient detail from the partially developed male genitalia to assign this material to $L$. mergatus. Indications are, then, either that larvae of $L$. mergatus show somewhat different case-building habits in different parts of the range, or that another species with larvae very similar to $L$. mergatus inhabits some of the same rivers. It may be noted here that these larvae were collected at an elevation of 5000 feet, although the other material of $L$. mergatus was all taken at elevations between 1800 and 3100 feet. Possibly associated with the greater elevation is the fact that the records indicate the Mandakini population is somewhat slower in development and adult emergence than the others that were sampled. It is also worth noting that these pupae were fixed to rocks above the water, the level evidently having dropped after their pupation, but alive and apparently in good condition.

Habitat and Biology. Larvae and pupae of this species were collected in turbulent rivers of medium to large size, flowing over rocky beds, some supporting dense algal growths. Elevations range from 1800 to 5000 feet (see preceding section), in heavily forested country. Adults were collected only in May, although the records of pupae on 29 May would mean the flight period would be extended at least into June.

Dr. Schmid's notes indicate that larvae and pupae of $L$. mergatus are always found isolated and never in groups as are the other species he observed. The larval cases are usually fastened to the vertical sides of rocks; the pupal cases in similar situations or beneath the rocks. The exterior surface of the pupal cases harbours the sand tubes of chironomid larvae and the mebranous cocoons of simuliid pupae.

Material Examined (all collected by F. Schmid). INDIA, Assam, North East Frontier Agency, Kameng Frontier Division: Amatulla, $1800 \mathrm{ft} ., 17$ May 1961, 7 o 3 o, at light; ibid., 17 May 1961, 4 o 9 \%, at light at the Bhairabkunda Chu (River); ibid., 24 May 1961, 1 o 2 \%, at light; ibid., $2000 \mathrm{ft} ., 25$ May 1961, 2 \& 3 o , at light; ibid., $2000 \mathrm{ft} ., 11$ March 1961, many larvae; Lifakpo, $3100 \mathrm{ft}$., 15 May 1961, 5 o 8 \%, at light at the Bhairabkunda Chu; ibid., 5 pupae; Lungdur, $2800 \mathrm{ft}$., 16 May 1961, 1 ô, at light; ibid., 7 o 4 , at light at the Bhairabkunda Chu. Pauri Garhwal: Khumyara, $5000 \mathrm{ft} ., 4$ May 1958, 8 larvae, tributary of Mandakini R.; ibid., 28 May 1958, 1 prepupa; Ugsara, 4500 ft., 29 May 1958, many larvae and pupae, tributary of Mandakini R. 
Distribution. Originally described from Sikkim, with an unassociated female from Assam thought to be of this species (Kimmins 1950), L. mergatus has not subsequently been recorded. The information offered here provides additional evidence for its occurrence through a wide band of the Himalayas from Pauri Garhwal (west of Nepal) to the North East Frontier Agency of Assam.

\section{Limnocentropus rectus Kimmins}

Limnocentropus rectus Kimmins 1950, p. 601, fig. 7.

Larva (Fig. 6). Although the species can be identified by the characters given in the key, no means have yet been found to unequivocally distinguish between the larvae of this species and $L$. himalayanus before the modifications to the pupal case are completed. Larval sclerites associated with pupae of both species are available, and no differences are apparent between them. Larvae from West Bengal, in agreement with the characters exhibited by the shed sclerites, and clearly too large to be L. himalayanus, are assumed to represent $L$. rectus. The specimens here described and illustrated (Fig. 6) are of this series.

Length of full-grown larva $20 \mathrm{~mm}$. Larva essentially as in L. mergatus, but muscle scars light in colour and the anterior margin of the frontoclypeus without a dark band. Sclerites of the submentum shorter than in $L$. mergatus (Fig. 4), extending anteriorly only as far as the base of the stout seta. Ventral surface of the first abdominal segment with only a few hairs, usually no more than six. Lateral line well-developed, distinct from $L$. mergatus, extending from abdominal segments III to VIII inclusive. Gills short and thick as in L. mergatus, but by contrast occurring only in the posterodorsal position of segments $\mathrm{V}$ to VIII inclusive. In the full-grown larvae a very small gill rudiment is apparent in the posterodorsal position of segment IV in about one-half of a series of ten larvae.

The larval case (Fig. 11a) is up to $25 \mathrm{~mm}$ in length, and with proportions similar to the case of $L$. mergatus. The case is constructed for the most part of small flat stones, with only a few pieces of bark. Corneous spikes of silk on the wall of the case are not made by larvae of this species as they are by $L$. mergatus. The mooring cable of the larval case is variable in length, ranging in the material at hand from 5 to $20 \mathrm{~mm}$, and is attached more or less perpendicularly to the long axis of the case because these larvae usually fix their cases on the upper horizontal surfaces of rocks.

Prior to pupation the mooring cable is reduced to a very short stalk as in L. himalayanus (Fig. 10), but the larva does not build a flange around the anterior opening of the case as it does in that species. Unique among all the larvae known, however, is the pre-pupation behaviour in which it would appear that a lunate excision is made in the wall of the case (Fig. 11c). The walls of the case are fastened together by a silken suture along this excision, with a small hole left at its anterior-most point. The interior of the case is sealed off with silk at the posterior extremity of the excision, with the result that the capacity of the pupal case for internal passage of a 
current of water must be little different than in the other species now known. The relatively small posterior opening of this pupal case, in comparison with the opening in larval cases, suggests that the portion behind the excision has, in fact, been added, although no clear demarcation is apparent in the wall.

Pupa (Fig. 13). Essentially as in L. mergatus, except for the anal processes which are much more slender throughout. The anal processes of $L$. rectus are, in fact, similar to those of $L$. himalayanus, but they taper posteriorly throughout most of their length. Length of pupa: 14-17 mm. Length of pupal case: $27-30 \mathrm{~mm}$.

Habitat and Biology. The single collection of pupae of this species was taken in a very turbulent river of medium size with a rocky bed supporting heavy algal growths (Assam: Lifakpo, $3100 \mathrm{ft} ., 15$ May). Of considerable interest is the fact that pupae of $L$. himalayanus were taken in the same collection. The larvae collected in West Bengal, and believed to be L. rectus, were living in cold, torrential streams, again supporting much algae.

Dr. Schmid's field notes record that he was unable to distinguish between larvae of $L$. rectus and $L$. himalayanus. He found the pupal cases of $L$. rectus both isolated and in groups, but not fastened one to another, and occasionally with a small piece of wood fastened across the silken covering of the anterior opening.

The pupal cases provide resting places for the same sort of varied fauna as do those of L. mergatus.

Material Examined (all collected by F. Schmid). INDIA, Assam, North East Frontier Agency, Kameng Frontier Division: Amatulla, 1800 ft., 17 May 1961, 2 o 1 \%, at light at the Bhairabkunda Chu (River); Lifakpo, 3100 ft., 15 May 1961, 6 pupae, Bhairabkunda Chu. West Bengal: Dilpa, Bara Hata, 6600 ft., 21 March 1959, many larvae, heađwaters of Rithu Kola.

Distribution. This species has not been recorded since its original discovery in the Khasi Hills of Assam (Kimmins 1950). Additional records provided here extend this range to the Himalayas in northern Assam and, assuming the larvae from West Bengal are correctly identified with this species, some short distance west of Assam, as well. 


\section{Limnocentropus himalayanus Martynov}

Limnocentropus insolitus himalayanus Martynov 1930, p. 91.

Limnocentropus insolitus himalayanus Mosely 1935, p. 132, pl. 12, figs. 32-33.

Limnocentropus fletcheri Mosely 1935 ,

p. 132, pl. 13, figs. 34-37. NEW SYNONYMY

Limnocentropus himalayanus Kimmins 1950, p. 599, fig. 6.

Adults (Figs. 16, 19). The major part of the adult material involved in this study is assigned to this species, and it comprises many series of associated males and females. A wide range in size is evident, with fore wing lengths ranging from 7 to $11 \mathrm{~mm}$ for males, and from 12 to $15 \mathrm{~mm}$ for females. The males are in essential agreement with the description of L. fletcheri Mosely from Sikkim (5000 ft., 18-30 April 1922), although there are some differences in shape and proportion of the tenth segment and claspers (Fig. 16). Variations exist in the material available to me within series of specimens from the same locality, and to a more marked degree among different localities. Those illustrated represent the extreme conditions seen, and there are many intermediates. These seem best interpreted as variants within a single species.

The females associated with these males are in essential agreement with the published data on the holotype female of L. himalayanus Martynov from Sikkim (Tsung-tang, $6000 \mathrm{ft}$., 24 April 1924). The most useful diagnostic characters for the females of this genus now appear to be the pattern of sclerotization and pigmentation on the sternum of the ninth abdominal segment and the form of the internal genitalic structures (Figs. 17-21), but these have not heretofore been available. Mr. D. E. Kimmins of the British Museum (Natural History) has kindly compared associated females of my material with the holotype of $L$. himalayanus with particular attention to these characters. In his opinion they are conspecific, although the genitalia of the holotype specimen are rather more lightly sclerotized and pigmented.

Mosely's (1935) view that Martynov's holotype was not really conspecific with $L$. insolitus Ulmer has been confirmed by Kimmins (1950), and full specific status given to it. And the new evidence presented here now makes it necessary to designate $L$. fletcheri Mosely as a junior synonym of L. himalayanus Martynov.

Larva. Several series of associated mature pupae and prepupae of this species are available, but as indicated under the preceding species, the only reliable character known thus far for distinguishing between larvae of $L$. himalayanus and $L$. rectus is in the pre-pupal case-making behaviour, as indicated in the key. Even though several series of larvae are available which agree generally with the associated prepupae, clear evidence of their identity does not exist and the descriptive notes on the larva of the species are actually based on prepupae.

Length of full-grown larva $10-14 \mathrm{~mm}$. Similar to the larva of $L$. rectus 
in all morphological characters except that the gill rudiment in the posterodorsal position of abdominal segment IV has not been seen in any specimens.

Larval case constructed mainly of small, flat mineral fragments, much as in $L$. rectus. Mooring cable evidently variable in length, but rarely longer than the larval case (assuming that at least some of the unassociated larvae belong to this species, which is altogether likely in view of the fact that most of the specifically identifiable adult specimens are L. himalayanus). The cable is attached to the case more or less perpendicularly to its long axis because these larvae usually fix their cases on the upper horizontal surfaces of rocks.

Prior to pupation, the larva constructs a flange of stones around the anterior opening of the case (Fig. 10), a behavioural feature different from larvae of any other species now known. The mooring cable is very much shortened at this time, too, and provides a supporting rib for the flange of stones.

Pupa (Fig. 14). As in L. rectus, except that the anal processes do not taper gradually from base to apex. Length of pupa 10-14 mm. Length of pupal case $12-20 \mathrm{~mm}$.

Habitat and Biology. Two collections contain associated material of this species, and the general habitat is the same as for L. rectus and mergatusturbulent rivers with beds of large rocks. Collections of numbers of adults at two rather different habitats indicate, though, that the range of conditions under which larvae of this species can live may, in fact, be broader than for either L. mergatus or rectus: a small swampy rivulet (Pauri Garhwal: Tungnath, $7500 \mathrm{ft} ., 1$ June 1958); and a stream (Assam: Jhum La, 9000 ft., 31 May 1961), flowing at that date but which had been dry in March. L. himalayanus has also been taken over a wider range of elevations, 2100 to 9000 feet, than either L. mergatus or rectus. A broader range of larval habitats for $L$. himalayanus is, in fact, consistent with the vast superiority in numbers of individuals and localities represented in the material available to me. Adults were collected through the months of April to July. The variations in size and structure noted above show no particular concordance with either time or elevation.

Although adults of $L$. mergatus and rectus are strongly nocturnal in habit, $L$. himalayanus adults are active during the day, as well as at night. Numbers of adults are on the wing during the warmest hours of the day, flying up to heights of 10 to 15 metres. Females were observed to carry their eggs in a mass at the end of the abdomen as do the females of Brachycentrus.

Notes by Dr. Schmid also indicate that the larvae of this species usually occur together in large numbers on the upper horizontal surfaces of rocks, but that the cases are spaced apart at regular distances. The pupal cases usually occur in compact masses of 50 to 200 individuals on the under surfaces of rocks or on vertical surfaces if protected from the full force of 
the current. Sometimes the cases are fastened one to another by the short mooring cables to form simple or bifurcated chains of 3 to 15 individuals (Fig. 10b). Although he was unable to distinguish between larvae of $L$. himalayanus and rectus, the vast numerical superiority of the former in all of his collections of identifiable material suggest that his notes apply to this species.

The anterior opening of the pupal case is generally directed into what current is present. Dr. Schmid records finding one set of some 150 pupal cases arranged on the under surface of a stone around the circumference of a circle $50 \mathrm{~cm}$ in diameter, with each case on a slight tangent facing the centre, indicating, he believes, a circular whirl of the current under the stone. The pupal cases of this species also provide living sites for various dipterous insects.

Material Examined (all collected by F. Schmid unless otherwise specified). INDIA, Assam, North East Frontier Agency, Kameng Frontier Division: Ankaling, 2100 ft., 26 May 1961, 1 ô, at light; Bilo La, 5800 ft., 9 June 1961, 1 o 1 q , at light; ibid., $6000 \mathrm{ft}$, 10 June 1961, 1 \%, at light; Dirang Dzong, $5600 \mathrm{ft}$., 23 April 1961, 12 ô, by net; ibid., $5300 \mathrm{ft}$., 24 April 1961, 1 으, by net; Jhum La, 9000 ft., 31 May 1961, 31 o , at light; Kalaktang, 4000 ft., 14 May 1961, 19 o 3 o , at light; Kuijjalong, 4500 ft., 28-30 June 1961, 1 q , at light; Lifakpo, 3100 ft., 15 May 1961, 9 ô, by net; ibid., 15 of 1 o at light; ibid., 2 \& 18 o , at light at the Bhairabkunda Chu (River); ibid., many pupae, Bhairabkunda Chu; Lungdur, 2800 ft., 16 May 1961, $1 \hat{\delta}$, by net; ibid., $2 \hat{\delta}$, at light; ibid., $7 \hat{\delta} 1$ o, at light at the Bhairabkunda Chu; Talung Dzong, 7800 ft., 4-5 June 1961, 2 o, at light. Pauri Garhwal: Binaik Chatti, 7000 ft., 1-2 July 1958, 1 of, at light; Chamoli, 3800 ft., 3 June 1958, 1 o , at light; Dolgabeta, 8000 ft., 30 May 1958, 2 o , by net; Duldhar, 4500 ft., 2 June 1958, 5 o 2 \%, at light; Khumyara, 27-28 May 1958, $5 \hat{\delta} 4$, at light; ibid., 5000 ft., 4 May 1958, many pupae and prepupae, tributary of the Mandakini R.; Tungnath, $7500 \mathrm{ft}$., 1 June 1958, 3 ? , by net during the day; Ugsara, $4500 \mathrm{ft} ., 29$ May 1958, 6 क 2 \%, at light. Teri Garhwal: Gawana, 6000 ft., 22-24 May 1958, 6 क 3 ㅇ, at light. Sikkim: Dentham, 4500 ft., 4 June 1959, $1 \hat{\delta}$, at light; Dikchu, 2300 ft., 9 May 1959, $2 \hat{o}$, at light; Manu, 4920 ft., 10 May 1959, 1 ô, at light; Sardong, 2600 ft., 6 April 1959, 1 ô, at light; Singbeng, $4920 \mathrm{ft}$., 26 April 1959, 1 ô, by net; ibid., 30 oे 10 ㅇ, at light; Tinglin, $2950 \mathrm{ft} ., 8$ April 1959, 1 ô, at light.

Distribution. This species has heretofore been recorded from Sikkim (Mosely 1935) and from north-eastern Burma (Kambaiti, 7000 ft., 25 May-11 June 1934; Kimmins 1950). The abundance of material now available shows that it also occurs over a broad segment of the Himalayas from Garhwal (west of Nepal) to north-eastern Assam. 


\section{Limnocentropus insolitus Ulmer}

Limnocentropus insolitus Ulmer 1907, p. 13.

Kitagamia montana Iwata 1927, p. 215, figs. 154-9.

Known extensively in Japan, this was for many years the only species known in the genus. Occurrence in several localities in China has also been recorded (Ulmer 1925, 1932). The larva has been described by Tsuda (1936), and the larva and pupa completely by Ulmer (1955). Little, in fact, need be added to Ulmer's work on this species, and the larva is treated here largely to make the comparative notes and keys as complete as present knowledge permits.

Larva (Fig. 5). Length of larva $18 \mathrm{~mm}$. Essentially similar to L. rectus and himalayanus, with muscle scars light in colour, distinguished by the lateral band of dark colour on the mesal plates of the meso- and metanota, as indicated in the key. Gills as in L. rectus and himalayanus except that a well-developed gill is consistently present in the posterodorsal position of abdominal segment IV. Lateral line less pronounced than in L. rectus and himalayanus.

The larval case is constructed largely of pieces of plant material, but of the typical form, and about $20 \mathrm{~mm}$ in length; diameter of the anterior end $4 \mathrm{~mm}$, of the posterior about $2 \mathrm{~mm}$. The mooring cable is slender as in $L$. rectus, and in the two larvae available to me, 5 and $10 \mathrm{~mm}$ in length respectively. Ulmer (op. cit.) gives measurements of the cable as 25-30 $\mathrm{mm}$ in iength. Assuming my specimens were not approaching pupation, there would then seem to be considerable variation in the length of this part of the case.

Prior to pupation the posterior end of the case is modified as in $L$. mergatus (Fig. 9). The mooring cables in the four pupal cases available to me range in length from $10-15 \mathrm{~mm}$.

Pupa. Essentially as in L. mergatus (Fig. 12), with the anal processes shaped much as in $L$. rectus (Fig. 13). Length of pupa approximately 12 $\mathrm{mm}$; length of pupal case $20 \mathrm{~mm}$.

Habitat. Iwata (1927) records this species from rapid sections of rivers in Japan.

Material Examined. JAPAN: Tochigi Pref., Nikko, 11 May 1957, 2 larvae, M. Tsuda; no data, 1 larva, 4 pupae.

\section{Limnocentropus sp.}

Larva (Fig. 7). A series of five larvae, labelled Siam, 1929, H. M. Smith, Acc. 107725 , is available from the U.S. National Museum. Although these specimens have evidently been dried out at some time, and are in poor condition, they do show several unique characters. Because of this, and on the basis of distribution, it is likely that these are the larvae of another species of Limnocentropus. No species of this family has been recorded 
from Thailand, although two species, L. bifidus Kimmins and L. moselyi Kimmins, are both known from neighbouring north-eastern Burma. Of these two, the adults of $L$. moselyi are too small to have arisen from these rather large larvae. In $L$. bifidus, on the other hand, males have a fore wing length of $16 \mathrm{~mm}$, even somewhat larger than the males of $L$. mergatus. On the basis of the structure of the male genitalia, L. bifidus seems closely allied to L. mergatus (Kimmins 1950). Thus, in view of the close similarity in structure and size between these larvae and those of $L$. mergatus, there is some possibility that this is the larva of $L$. bifidus.

Length of larva $22 \mathrm{~mm}$ (approximate, owing to the condition of the specimens). Very similar in most characters to $L$. mergatus, with dark muscle scars on the head and thorax. Distinct from L. mergatus, however, in several well-defined characters, as indicated in the key; and also in that each sclerite of the submentum extends anterad only as far as the base of the stout seta.

No larval cases are available with these specimens.

\section{Limnocentropus \\ (unidentifiable immature material)}

Listed in the foregoing as material examined are all of the larvae and pupae available for this study which can be placed to species with some assurance. Several other collections are also available but, largely because of the difficulty in distinguishing between larvae of $L$. rectus and himalayanus, these can be at best only tentatively identified. Nonetheless this material amounts to a significant proportion of the total of the immature stages available to me, and in view of the extreme paucity of similar material in museum collections, a listing of these specimens seems justifiable. Tentative identifications are suggested in some cases, with an indication of the supporting evidence. Unless otherwise indicated, material is collected by F. Schmid.

Material Examined. INDIA, Assam, North East Frontier Agency, Kameng Frontier Division: Amatulla, 2000 ft., 11 March 1961, 11 larvae ( $L$. rectus?, collected here later as adult, larvae too large to be L. himalayanus); ibid., 16 Oct. 1961, many small larvae (L. rectus?, as above); Brukpatarnchen, 4000 ft., 18 March 1961, 1 small larva; Dirang Dzong, 5300 ft., 11 April 1961, many larvae (L. himalayanus ?, collected here later as adult); Kalaktang, 4000 ft., 10 Oct. 1961, many larvae (L. himalayanus ?, collected here as adult); Lifakpo, $3100 \mathrm{ft}$., 15 March 1961, many larvae. Sikkim: Naya Bazar, 1060 ft., 16 March 1959, many larvae. NEPAL (all material collected by Dr. H. Janetschek): Changma, 2200 m, 13 June 1961, 2 empty pupal cases ( $L$. himalayanus ?, conspicuous collar of stones around anterior opening of case, known as yet only in this sp.); Bhandar, 1960 m, tributary of the Likhu Kola, 22 April 1961, 4 larvae; Numbur, 1700 m, tributary of the Likhu Kola, 23 April 1961, 2 larvae; Jiri, 2000 m, Jiri Khola, 20 April 1961, 1 larva. 


\section{Key to the females of Limnocentropus (in part)}

1. Median plate of the ninth sternum heavily sclerotized and pigmented, with prominent posterolateral winglike extensions (Figs. 17, 20)

Median plate of the ninth sternum heavily sclerotized and pigmented, without prominent posterolateral wing-like extensions (Figs. 18, 19, 21)

2. Median plate semi-circular in outline, each posterolateral extension broadly triangular (Fig. 17) (Assam, West Bengal)

L. rectus

Median plate vase-shaped, a deep V-shaped cleft between the two narrowly triangular posterolateral extensions (Fig. 20) (Japan, China)

L. insolitus

3. Median plate with base narrower than central portion

(Fig. 18) (central and eastern Himalayas)

L. mergatus

Median plate with base wider than central portion

(Figs. 19, 21)

4. Sclerotized connections between ovoid spermatheca and genital passage narrower than spermatheca in ventral view (Fig. 19) (central and eastern Himalayas, Burma)

Sclerotized connections between spermatheca and genital passage wider than spermatheca in ventral view (Fig. 21) (Burma)

L. himalayanus

L. moselyi

\section{Acknowledgments}

For the opportunity of studying this very rich collection of obscure Trichoptera, I am indebted to Dr. Fernand Schmid, Entomology Research Institute, Canada Department of Agriculture, Ottawa. Dr. Schmid's field notes on larval behaviour have been especially helpful. Prof. Matsunae Tsuda, Nara Women's University, Japan, provided specimens of $L$. insolitus Ulmer from Japan. Mr. D. E. Kimmins, British Museum (Natural History) kindly compared specimens with the holotype of L. himalayanus Martynov in the collection of that institution. The assistance of Dr. O. S. Flint, U.S. National Museum, in providing larval specimens from Thailand is acknowledged. Also acknowledged is additional material from Nepal, collected by Prof. $\mathbf{H}$. Janetschek, Institut für Zoologie der Universität Innsbruck, Austria, during his Khumbu Himal travel organized by the Research Scheme Nepal Himalaya. This was made available through Dr. Lazar Botoşaneanu, Bucharest. The illustrations were prepared by Mr. Anker Odum, artist in the Department of Entomology and Invertebrate Zoology, Royal Ontario Museum. This study is part of a continuing research project on the immature stages of Trichoptera supported by the National Science Foundation (G B 4021). 


\section{Literature Cited}

BADCOCK, R. M.

1961 The morphology of some parts of the head and maxillo-labium in larval Trichoptera, with special reference to the Hydropsychidae. Trans. R. Ent. Soc. Lond., vol. 113, pt. 10, pp. 217-248.

BOTOŞANEANU, L.

1963 Insecte . . . arhitecti si constructori sub apa. Editura stiintifica, Bucuresti, 246 pp.

CRICHTON, M. I.

1957 The structure and function of the mouth parts of adult caddis flies (Trichoptera). Phil. Trans. R. Soc. Lond., ser. B, vol. 241, no. 677, pp. 45-91.

HINTON, H. E.

1963 The ventral ecdysial lines of the head of endopterygote larvae.

Trans. R. Ent. Soc. Lond., vol. 115, pt. 2, pp. 39-61.

IWATA, M.

1927 Trichopterous larvae from Japan. Annotnes. Zool. Jap., vol. 11, no. 3, pp. 203-233.

KIMMINS, D. E.

1950 Indian caddis flies (Trichoptera). I. New species of the genus Limnocentropus Ulmer. Ann. Mag. Nat. Hist., ser. 12, vol. 3, pp. 590-603.

MARTYNOV, A. B.

1930 On the trichopterous fauna of China and eastern Tibet. Proc. Zool. Soc. Lond., 1930, pt. 1, no. 5, pp. 65-112.

MECOM, J. O. AND CUMMINS, K. W.

1964 A preliminary study of the trophic relationships of the larvae of Brachycentrus americanus (Banks) (Trichoptera: Brachycentridae). Trans. Am. Microsc. Soc., vol. 83, no. 2, pp. 233-243.

MOSELY, M. E.

1935 The Indian caddis-flies (Trichoptera). Pt. III. Inaequipalpia: Phryganeidae. J. Bombay Nat. Hist. Soc., vol. 38, no. 1, pp. 123133.

NIELSEN, A.

1942 Uber die Entwicklung und Biologie der Trichopteren mit besonderer Berücksichtigung der Quelltrichopteren Himmerlands. Arch. Hydrobiol., Stuttgart, Suppl., vol. 17, pp. 255-631.

1943 Postembryonale Entwicklung und Biologie der Rheophilen Köcherfliege Oligoplectrum maculatum Fourcroy. Biol. Meddr., vol. 19, no. 2, pp. 1-86.

ROSS, H. H.

1959 Trichoptera. In Ward and Whipple, Freshwater biology. 2nd ed., W. T. Edmondson, editor. John Wiley and Sons, New York, pp. 1024-1049.

1967 The evolution and past dispersal of the Trichoptera. A. Rev. Ent., vol. 12, pp. 169-206.

TINDALL, A. R.

1963 The skeleton and musculature of the thorax and limbs of Limnephilus sp. (Trichoptera: Limnephilidae). Trans. R. Ent. Soc. Lond., vol. 115 , pt. 14, pp. 409-477. 
TSUDA, $M$.

1936 Untersuchungen über die Japanischen Wasserinsekten. I. Kitagamiidae, eine neue Familie der Trichopteren. Annotnes. Zool. Jap., vol. 15, no. 3, pp. 394-399.

1942 Japanische Trichopteren I. Systematik. Mem. Coll. Sci. Kyoto Univ., ser. B, vol. 17, no. 1, art. 6, pp. 239-339.

ULMER, G.

1907 Trichopteren. In Collections zoologiques du Baron Edm. de Selys Longchamps: fasc. VI. Brussels. $121 \mathrm{pp}$.

1925 Beiträge zur Fauna sinica. III. Trichopteren und Ephemeropteren. Arch. Naturgesch., vol. 91, abt. A, heft 5, pp. 19-110.

1932 Aquatic insects of China, Article IV. Neue Chinesische Trichopteren, nebst übersicht über die bisher aus China bekannten Arten. Peking Nat. Hist. Bull. 1932-33, vol. 7, pt. 2, pp. 135-157.

1951 Köcherfliegen (Trichopteren) von den Sunda-Inseln (Teil I). Arch. Hydrobiol., Stuttgart, Suppl., vol. 19, pp. 1-528.

1955 Köcherfliegen (Trichopteren) von den Sunda-Inseln (Teil II). Larven und Puppen der Integripalpia, unter Berücksichtigung verwandter Formen und deren Literatur aus anderen Faunengebieten. Arch. Hydrobiol., Stuttgart, Suppl., vol. 21, pp. 408-608.

WIGGINS, G. B.

1959 A new family of Trichoptera from Asia. Can. Ent., vol. 91, no. 12, pp. 745-757.

1965 Additions and revisions to the genera of North American caddisflies of the family Brachycentridae with special reference to the larval stages (Trichoptera). Can. Ent., vol. 97, no. 10, pp. 1089-1106. 


$(124=$ 
LIBRARY

ROYAL ONTARIO MUSEUM 

19 
